\title{
Movimientos estudiantiles en Polonia y México de 1968: un estudio comparativo*
}

\author{
Student movements in Poland and Mexico in 1968: Comparative studies
}

\author{
Izabela Tkocz ${ }^{* *}$ \\ Jesús Adolfo Trujillo Holguín***
}

Resumen: El artículo conmemora los movimientos estudiantiles de 1968 en Polonia y México, y al mismo tiempo se toma para reflexionar sobre la crisis de credibilidad del Estado moderno, su capacidad para responder a las demandas sociales, y sobre la efectividad de los métodos empleados para el control de las masas dentro de los sistemas políticos con características autoritarias. Las preguntas de investigación son: ¿Existen similitudes en el desarrollo de las protestas estudiantiles en Polonia y México?, ¿En el perfil de los manifestantes? ¿En la manera de reaccionar del gobierno? ¿Son los movimientos estudiantiles reacciones semi-racionales a condiciones anormales de la tensión estructural en las principales instituciones sociales? El primer caso se conoce comúnmente como Aliya en Polonia y el segundo como Matanza de Tlatelolco.

Palabras Clave: México, Polonia, Movimientos estudiantiles, 1968.

\begin{abstract}
This paper commemorates the student movements of 1968 in Poland and Mexico, and at the same time it is taken to reflect about the crisis of credibility of the modern State, its capacity to respond to social demands, and the effectiveness of the methods employees for the control of the masses within the political systems with authoritarian characteristics. The research questions are: are there similarities in the development of the student protests in Poland and Mexico? In the profile of the protesters? In the way that the government reacts? Are student movements semi-racionales reactions to abnormal conditions of structural strees on the main social institutions. The first case is commonly known as Aliya in Poland, and the second as Matanza de Tlatelolco.
\end{abstract}

Keywords: Mexico, Poland, Student movements, 1968

Recibido: 1 febrero 2019 Aceptado: 26 junio 2019

\footnotetext{
* Este trabajo es parte de la investigación titulada La influencia de la ideología socialista soviética en la cultura y educación de Chibuabua en periodo 1930 a 1940, realizada en la Facultad de Filosofía y Letras de la Universidad Autónoma de Chihuahua, con financiamiento del Programa Nacional de Posgrados de Calidad del Consejo Nacional de Ciencia y Tecnología (PNPC-CONACyT). Periodo de duración: 2016-2019.

** Polaca, Autora principal. Historiadora / Catedrática de la licenciatura en historia, Facultad de Filosofía y Letras de la Universidad Autónoma de Chihuahua, Programa Nacional de Posgrados de Calidad del Consejo Nacional de Ciencia y Tecnología (CONACYT),2016-2019izatkocz@hotmail.com

${ }^{* * *}$ Mexicano Co-autor, Doctor en Educación / Profesor-Investigador en el área de posgrado Facultad de Filosofía y Letras de la Universidad Autónoma de Chihuahua. Programa Nacional de Posgrados de Calidad del Consejo Nacional de Ciencia y Tecnología (CONACYT), 2016-2019 jatrujillo@uach.mx
} 


\section{Introducción}

El objetivo principal de esta investigación es generar conocimiento sobre la historia presente en países del bloque socialista para contrastarlo con lo ocurrido fuera de la Cortina de Hierro. Existe la convicción de que este tipo de estudios permite comprender mejor la historia, los mecanismos que la mueven y la universalidad de ideas que acompañan a los seres humanos, independientemente de su ubicación geográfica, cultura y sistema político en que se desenvuelven.

En el texto se analizan los antecedentes y consecuencias de los movimientos estudiantiles en Polonia y México, acentuando el enfoque en el caso polaco, dado que las publicaciones hispanoparlantes ofrecen pocos datos acerca del descontento que se presentó en el entonces bloque socialista. Analizar estos hechos ayuda a comprender mejor los procesos históricos del siglo XX. Para realizar el trabajo se recurrió principalmente a fuentes secundarias que permitieron conocer a fondo las ideas y valores que estimularon la ola de movimientos estudiantiles en la década de los sesenta, así como sus consecuencias. El uso de fuentes primarias de Polonia fue restringido por la distancia geográfica y solo se consultaron las que se encuentran en soporte digital abierto. En este caso se tuvo acceso a las memorias de los manifestantes, a las publicaciones oficiales del gobierno, a los artículos y libros publicados por los historiadores polacos. La narrativa se enriquece con imágenes de la época.

El trabajo se relaciona de manera indirecta con el proyecto de investigación titulado La influencia de las ideas socialistas soviéticas en la cultura y educación de Chibuabua en el periodo 1920 a 1940, realizado actualmente en la Facultad de Filosofía y Letras de la Universidad Autónoma de Chihuahua, México. Es también una invitación a la reflexión en torno al abuso de poder por parte del Estado en relación a sus ciudadanos y su inflexibilidad para hacer los cambios necesarios.

\section{Teoría de los movimientos sociales en el siglo XX}

En el análisis de los movimientos sociales del siglo XX, relacionados también con el descontento estudiantil de 1968, cabe tomar en cuenta su actitud anti-estatal en el marco excesivo de control y autoritarismo del gobierno. Es importante mencionar la teoría de la conducta masiva, como la llama José María Aranda Sánchez en su artículo El Movimiento Estudiantily la Teoría de los Movimientos Sociales:

La explicación de la "conducta colectiva" es aún aceptada como de las pioneras en los estudios de movimientos sociales. En los seguidores de esa corriente estuvieron varios sociólogos de la Escuela de Chicago, como Ralph Turner y Lewis Killian; Talcott Parsons y su estructural funcionalismo, y sobre todo Neil Smelser. Los defensores de esa orientación consideran a los movimientos sociales como reacciones semi-racionales a condiciones anormales de la tensión estructural, en las principales instituciones sociales. Esa tensión produce un inadecuado funcionamiento del sistema social en su conjunto. Smelser explicaba el mecanismo de la emergencia de los movimientos sociales, donde éstos son el síntoma y expresión de una sociedad enferma. Una sociedad sana no tendría movimientos sociales, ya que cuenta con una formalidad política y "normas" para la participación social. La teoría de la acción social aportó interesantes reflexiones a la inicial elaboración del funcionalismo, y actualmente las concepciones de la acción colectiva permiten un acercamiento al estudio de movimientos y organizaciones sociales. Aunque también se plantean diferencias entre la acción colectiva y el movimiento social, sobre todo en el grado y alcances de la primera, así como en los objetivos de mayor importancia social en el caso de los movimientos sociales". ${ }^{1}$

${ }^{1}$ José Aranda Sánchez, El Movimiento Estudiantil y la Teoría de los Movimientos Sociales, Convergencia. Revista de Ciencias Sociales, vol. 7, núm. 21, enero-abril, 2000 Universidad Autónoma del Estado de México Toluca, p. 226. 
Es importante mencionar que el activismo estudiantil, según Philip Altbach ${ }^{2}$, aparece en todo el mundo, entonces es muy difícil etiquetarlo como protestas de los aburridos y malcriados jóvenes, o analizarlo solamente en el contexto de la actividad antitotalitaria y antiautoritaria. Más bien, independientemente del carácter político o ideológico, el movimiento estudiantil tiene carácter de contestación: "en general el activismo estudiantil tiene forma de oposición. Esta oposición contra la autoridad existente pude devenir de la izquierda o de la derecha o pude ser la expresión estructural de la cultura o religión". ${ }^{3}$

Los movimientos estudiantiles se pueden interpretar como forma de desobediencia, cuyo objetivo no solo es la destrucción del sistema político, sino evidenciar fallas y necesidades en los aspectos donde la sociedad no puede funcionar correctamente. Bauman ${ }^{4}$ reflexiona que -en este sentido- la protesta estudiantil es una herramienta de la democracia y es la forma institucionalizada de la desobediencia, con la función específica de vigilar aspectos públicos y hacer cambios políticos.

Según Arendt ${ }^{5}$ el acto de desobediencia aparece cuando no hay otra manera de cambiar ni corregir el sistema político: "la desobediencia civil aparece cuando un grupo de ciudadanos considera que los canales normales para hacer cambios no funcionan y cuando perciben que las críticas no serían escuchadas ni tomadas en cuenta, o -por el contrario- cuando el gobierno quiere hacer cambios, pero de manera poco legal y constitucional."'6

El acceso cada vez más abierto a la información y la educación provocaron el crecimiento de la conciencia ciudadana y los cuestionamientos hacia el gobierno eran casi inevitables. Los grupos de jóvenes que salían a protestar empezaron a hacerse cada vez más grandes; muchas veces no por la necesidad de cuestionar el poder, sino como consecuencia del inconsciente colectivo ${ }^{7}$ que les movía junto a sus compañeros. Con el tiempo se quedaron atrapados por la situación en la que participaban y se convertían en un manifestante más. Aquella fue una de las salidas a las tensiones en que vivía la sociedad, obligada muchas veces a fingir satisfacción por su gobierno, sin voz ni participación en la toma de decisiones. Además, el progreso rápido de la ciencia y la tecnología ya no concordaba con el estilo de vida de las generaciones anteriores que mantenían el poder político y social, provocando frecuentes choques de opiniones que, al ser constantemente oprimidas, se hicieron cada vez más violentas.

La reacción del Estado era eliminar la oposición de la manera más rápida posible para prevenir la expansión de los cuestionamientos y -ante todo- preservar su poder. Es importante también señalar que los tiempos de los gobiernos absolutistas parecían haber terminado con la Revolución francesa, pero el modelo del Estado paternalista y autoritario logró sobrevivir.

\section{El caso polaco}

El régimen socialista se estableció en Polonia por medio de los acuerdos establecidos en las conferencias entre los aliados, que asignaron el territorio polaco al control de la Unión Soviética. Por medio de la fuerza armada y las elecciones fraudulentas de 1947 se confirmó oficialmente la formación del nuevo gobierno ${ }^{8}$.

\footnotetext{
2 Philip Altbach, Comparative Higher Education, Greenwood Publishing Group, 1998.

3 Idem, p. 148.

${ }_{4}^{4}$ Zygmunt Bauman, The Present Crisis of the Universities, en: Leszek Nowak, Jerzy Brzeziński, Poznan Studies of the Philosophy of Science and the Humanities 50: "The Idea of The University”, Rodopi, Amsterdam, 1995.

${ }^{5}$ Hannah Arendt, Niepostuszeństwo obywatelskie (Desobediencia civil), Aletheia, Warszawa, 1999.

6 Idem, p.177.

7 Gustav Jung, Los arquetipos y lo inconsciente colectivo. Madrid: Trotta, 2002.

8 Andrzej Paczkowski, Pót wieku driejón Polski (Medio siglo de la historia de Polonia). Warszawa: Wydawnictwo Naukowe PWN, 2005.
} 


\section{Las elecciones fraudulentas en 1947}

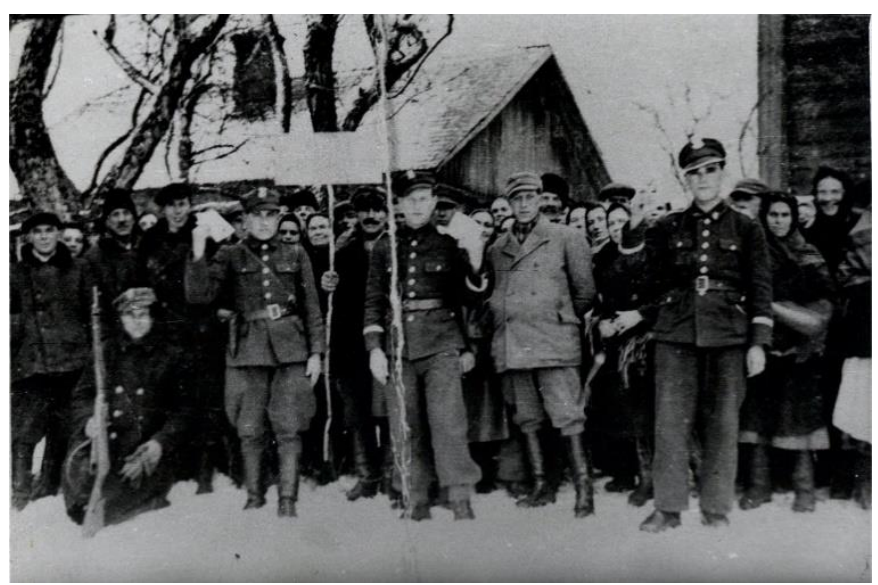

Fuente: Instituto de la Memoria Nacional (https://ipn.gov.pl/).

Para comprender mejor las causas de los movimientos estudiantiles de 1968 en Polonia es casi obligatorio remontarse a 1956, cuando surgieron los primeros brotes de inconformidad con desenlace trágico. El sistema represivo estalinista, caracterizado por la pobreza, la hambruna, la falta de libertad de expresión y el culto a la personalidad, ocasionó que una parte de las clases populares (particularmente los obreros) tomaran la decisión de manifestar su descontento e iniciar grandes huelgas y marchas de protesta.

Una de las más importantes tuvo lugar en el mes de junio en la ciudad de Poznań (Gran Polonia), cuando alrededor de cien mil manifestantes se formaron en una de las plazas principales para exigir a las autoridades cambios en la política. El gobierno respondió con fuerza brutal, usando tanques de guerra y armas del ejército contra los civiles, entre quienes se encontraban mujeres y niños. ${ }^{9}$ La primera muerte fue de un joven de 13 años de edad, llamado Romek Strzalkowski, quien posteriormente se convirtió en el símbolo de la lucha del pueblo contra el Estado corrupto. El número exacto de muertos y desaparecidos hasta hoy es desconocido. ${ }^{10}$

Los tanques de guerra en las calles de Poznań en 1956, durante las protestas de junio.

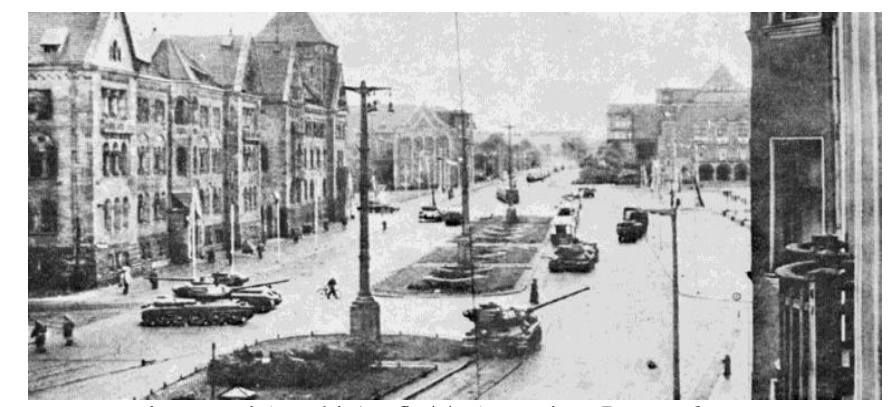

Fuente: Jaroslaw Maciejewski, Zofia Trojanowicz, Poz̧nański czermiec 1956, Poznań 1981.

\footnotetext{
${ }^{9}$ Jerzy Eisler, Polskie miesiace, czyli kryzys(y) w PRL (Los meses polacos, crisis en Polonia). Polonia, Wyd. EPUB, 2008.

10 Andrzej Paczkowski, (2005). Pót wieku driejón Polski (Medio siglo de la historia de Polonia). Warszawa: Wydawnictwo Naukowe PWN, 2005.
} 
Los hechos de Polonia fueron opacados mediáticamente por la rebelión en Hungría (octubre 1956), donde el motivo y las tácticas de opresión eran parecidas. Además, hubo otros eventos internacionales como la invasión al Canal de Suez o la XX Reunión del Partido Comunista de la Unión Soviética, donde se pronunció el discurso "secreto" del primer secretario del Comité Central, Nikolai Krushchev. ${ }^{11}$

La herida abierta en la sociedad polaca en 1956 provocó el rompimiento lento con el gobierno socialista soviético impuesto por Moscú después de la Segunda Guerra Mundial. Como consecuencia de las protestas, hubo persecución de opositores y represalias en contra de los trabajadores: normas laborales rígidas para poder cumplir con los planes de desarrollo económico, impuestos ocultos dentro de los precios, horarios adicionales de trabajo, decremento de los sueldos y escasez de productos básicos como la carne. El descontento social se manifestó mediante severas críticas, cuestionamientos y discusiones acerca del socialismo. El gobierno solamente prometió cambios democráticos en los discursos oficiales ${ }^{12}$.

Los sueldos en los años 1966-1970 se situaban entre 850 a 2296 PLN (Polski Zloty), en cambio el precio de un traje era de 2000 PLN y un televisor alrededor de 700 PLN $^{13}$. Esto ocasionó que incrementaran las huelgas de los obreros y las críticas hacia el gobierno fueron cada vez más comunes entre los grupos de intelectuales, especialmente en las grandes universidades.

Fuera del ambiente polaco convulso, el mundo experimentaba cambios importantes al iniciar la década de 1960. Apareció la píldora anticonceptiva, llegó la revolución cultural con el movimiento hippie, la música (The Beatles, The Rolling Stone, Brigitte Bardot), la revolución cultural de Mao Tse Tung, drogas, pop art, el emblema make love not war, la emancipación de la población de color en los Estados Unidos y, como lo más importante de 1968, los movimientos estudiantiles en diferentes partes del mundo: Estados Unidos, México, Francia, Japón, Italia, Alemania Occidental y Yugoslavia. Todas estas novedades lentamente $-\mathrm{y}$ prohibidas- llegaron a Polonia e influyeron para que los jóvenes desearan participar y construir un mundo nuevo y mejor. Probablemente las ideologías marxista, trotskista, anarquista y maoísta — que sustentaba todos estos movimientos- se manifestaron en el slogan del Mayo francés: Seamos realistas, pidamos lo imposible14.

En 1968 la situación en Polonia se plantaba parecida a la de 1956. Los acontecimientos estudiantiles de marzo otra vez fueron opacados por el contexto internacional. La Primavera en Praga, las revueltas juveniles en Occidente (Francia, Alemania Occidental, Estados Unidos, entre otros), el apogeo de la guerra en Vietnam y la rivalidad entre soviéticos y chinos por la hegemonía dentro de la "familia" socialista acapararon la atención a nivel mundial.

\section{Polonia. Marzo de 1968}

En 1945, por medio de las elecciones supuestamente democráticas, se estableció el régimen socialista en Varsovia con un gobierno relacionado con Moscú y Stalin. Hasta 1953 (muerte de Stalin) se produjeron una serie de violaciones contra los derechos humanos y persecución de los opositores. Una parte del gobierno socialista estaba integrada por personas de origen judío, lo que provocó la equivocada identificación de lo socialista con lo judío y no polaco. La política cultural tenía carácter abierto y promovía muchas iniciativas judías. En 1956 cayó el gobierno relacionado con la línea estalinista y el que surgió luego, optó por realizar cambios como la promoción del nacionalismo y la mejora de las relaciones

\footnotetext{
11 Jerzy Eisler, Rok polski 68 (Año polaco 1968), Warszawa, PWN, 2006.

12 Andrzej Paczkowski, (2005). Pót wieku driejów Polski (Medio siglo de la bistoria de Polonia). Warszawa: Wydawnictwo Naukowe PWN, 2005.

13 Maty Rocznik Statystyczny (Anuario de estadística) 1969, Warszawa 1969, s. 286, 292.

14Jerzy Eisler, Polskie miesiace, csyli kryyysy) w PRL. (Los meses polacos, crisis en Polonia), Polonia, Wyd. EPUB, 2008.
} 
con la Iglesia Católica Romana. Estas simulaciones democráticas despertaron la esperanza de un mejor futuro entre la sociedad ${ }^{15}$.

El 8 de marzo de 1968, en la Universidad de Varsovia, tuvo lugar una gran manifestación de estudiantes contra la censura estatal que prohibía la presentación de la obra teatral titulada Vispera de los antepasados escrita en el siglo XIX por el gran poeta polaco Adam Mickiewicz. ${ }^{16}$

La demostración estudiantil fue atacada brutalmente por la milicia y la organización de los supuestos obreros, quienes consideraban el descontento juvenil como ofensa al gobierno comunista. Este acontecimiento está considerado como el inicio de Marzo 68, llamado así en la historiografía polaca. Fue una crisis política dentro del gobierno socialista en Polonia, provocada por varias casusas. Por un lado, la lucha interna en el partido socialista y, por otro, el descontento generalizado de la sociedad por los desvíos en el poder que produjeron corrupción, fraudes electorales, opresión de la oposición y censura. Por parte del gobierno se iniciaron las purgas de las personas incómodas, principalmente los opositores, llamados por la prensa oficial como inteligencia y un movimiento fuertemente antisemita ${ }^{17}$. Las protestas y marchas de 1968 estaban ligadas a los acontecimientos que surgieron en el mundo.

En la siguiente década no hubo cambios en la política, salvo lo que se mencionaba en los discursos. En 1967, como consecuencia de la guerra judío-árabe ${ }^{18}$, la Unión Soviética y el gobierno polaco rompieron relaciones diplomáticas con Israel y apoyaron a los palestinos. En el mismo contexto surgió un acercamiento del gobierno israelí con Estados Unidos, por lo tanto, se rompió la relación entre los socialistas polacos e israelíes. Aquí es importante recordar que el Estado israelí estaba formado por los judíos polacos, socialistas, sobrevivientes del Holocausto. ${ }^{19}$ Los movimientos antisemitas en Polonia se hicieron cada vez más fuertes; esto permitió hacer purgas de las personas incómodas por parte del régimen socialista.

En enero de 1968 inició en Checoslovaquia un movimiento que solicitaba cambios democráticos en la política, conocido posteriormente como Primavera de Praga. La influencia checa llegó a Polonia, especialmente a las universidades. Muchos intelectuales que criticaban al gobierno tenían raíces judías ${ }^{20}$. Combinando el nacionalismo y antisemitismo empezaron las persecuciones ${ }^{21}$.

Mientras tanto en Polonia, en enero de ese año, se presentó la obra del poeta polaco Adam Mickiewicz ${ }^{22}$, Vispera de los antepasados, que la censura quitó de cartelera considerándola como antisoviética y anti-rusa, lo cual provocó manifestaciones. A partir de entonces el movimiento de los opositores del gobierno socialista polaco cobró fuerza.

El 30 de enero fueron arrestadas 35 personas durante las manifestaciones y muchos otros fueron golpeados. Dos estudiantes de la licenciatura en historia -Adam Michnik y Henryk Szlajfer- informaron sobre este hecho a la prensa francesa y a la Radiodifusora Europa Libre. El movimiento opositor se conoció en Europa ${ }^{23}$.

\footnotetext{
15 Jerzy Eisler, Rok polski 1968 (Año polaco 1968), Warszawa, PWN, 2006.

16 Para entonces la obra era considerada fuertemente antirusa y fue escrita cuando Polonia no existía como Estado. Adam Mickiewicz la publicó en entre 1823 a 1860. El reparto de su territorio entre Rusia, Prusia y Austria concluyó en 1795.

17 Jerzy Eisler, Polskie miesiace, csyli krysyss(y) w PRL. (Los meses polacos, crisis en Polonia), Polonia, Wyd. EPUB, 2008.

${ }_{18}$ Conocida también como Guerra de 6 días, donde Israel recibió apoyo de los Estados Unidos y los países árabes de la Unión Soviética, dentro de la llamada Guerra Fría.

${ }^{19}$ Norman Finkelstein, La industria del Holocausto, Verso, 2003.

${ }^{20}$ La población de judíos polacos que lograron sobrevivir a la Segunda Guerra Mundial en su mayoría constaba del grupo de los intelectuales y artistas de orientación socialista, críticos del régimen socialista soviético en Polonia.

21 Wojciech Suleja, Marzec 68 na dolnym Slasku- anatomia protesty (Marzo 68 en Silesia Baja - anatomia de la protesta), Warszawa: Instytut Pamięci Narodowej, 2006.

22 Poeta del siglo XIX, considerado uno de los más grandes de legua polaca, escribía en periodo de reparto de Polonia entre Rusia, Prusia y Austria. La obra Vispera de los antepasados es abiertamente anti-rusa y estaba prohibida en la Polonia estalinista.

${ }_{23}$ Bogdan Hillebrandt, Marzec 1968. Geneza i przebieg wypadków, (Marzo 1968, genesis y trayectoria de los eventos), Polonia, Warszawa, 1986.
} 
Protesta estudiantil, marzo del 68

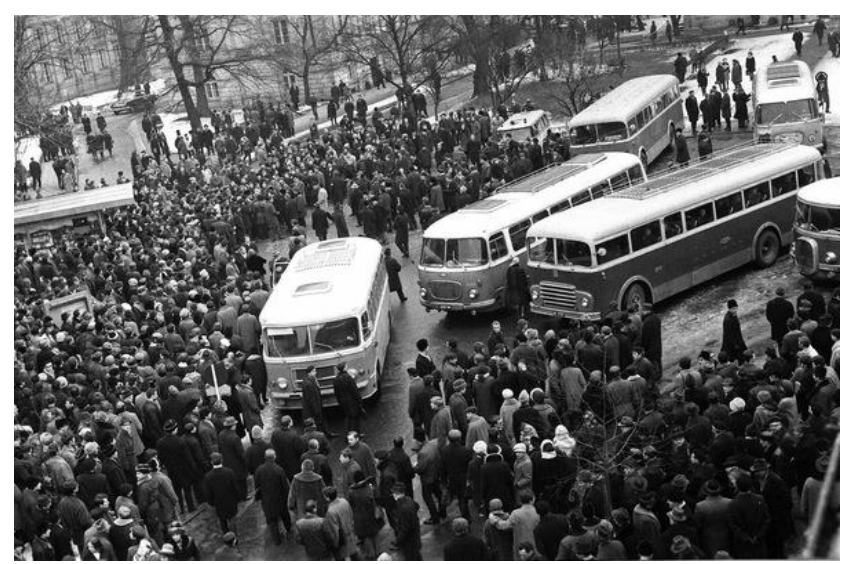

Fuente: Instituto de la Memoria Nacional (https://ipn.gov.pl/)

Las autoridades educativas tomaron la decisión de relegar de la comunidad estudiantil a los alumnos que se comunicaron con la prensa extranjera. Los estudiantes de la Universidad de Varsovia iniciaron una manifestación contra esta decisión y a favor de la democratización de la vida política en el país. El 8 de marzo, en la Universidad de Varsovia, los estudiantes organizaron una reunión en la que defendían las libertades de los ciudadanos citando el artículo 71 de la Constitución Polaca. ${ }^{24}$ Se hizo una carta en la cual solicitaban el regreso de Michnik y Szajfer a la Universidad, como también otros estudiantes que eran relegados. La reunión tenía una trayectoria muy tranquila, pero al momento de culminar entraron a la plaza universitaria varios camiones con la palabra Turistas. Para sorpresa de todos los asistentes bajaron las fuerzas policiacas, todos vestidos como civiles. Aparecieron también los miembros del Partido Socialista Juvenil, gritando: Los rebeldes fuera. Queremos estudiar en paz. Los estudiantes respondieron con: Libertad, Gestapo. ${ }^{25}$

Protesta estudiantil, marzo del 68.

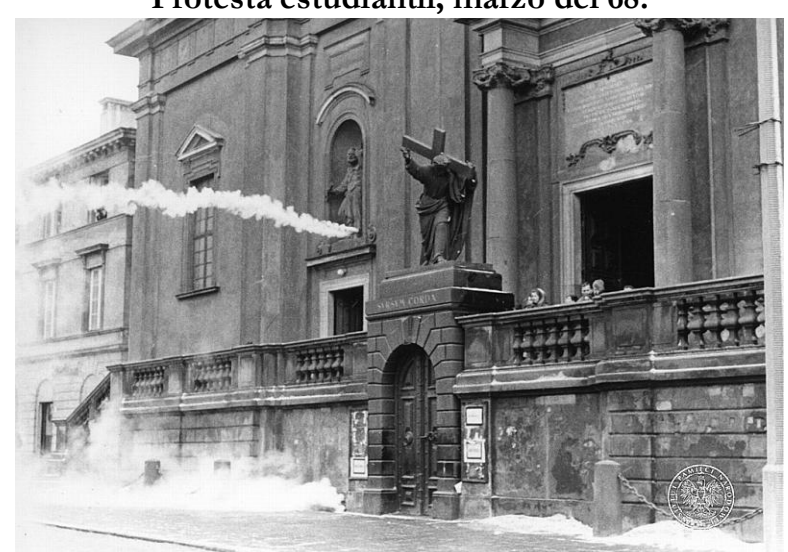

Fuente: Instituto de la Memoria Nacional (https://ipn.gov.pl/)

\footnotetext{
${ }^{24}$ El Artículo 71 de Constitución de Polonia de año 1952 dice: 1. El estado polaco garantiza a todos los ciudadanos la libertad de palabra, prensa, reuniones, marchas y manifestaciones. 2. Para que se pueda cumplir con el punto 1 se destina a usar por los ciudadanos y sus organizaciones imprenta, papel, edificios y salones públicos, medios de comunicación, radio como también todos otros recursos indispensables. (konstytucja.pl/konstytucja-prl-1957/).

${ }^{25}$ Tomasz Leszkowicz, Co sie zdaryyto 8 marca 1968 roku? (Que pasó en 8 de marzo 1968?), histmag.org.
} 
Los profesores de la Universidad trataron de negociar entre la multitud, pero alrededor de las 14:30 horas llegaron más carros con policías armados y empezó la violencia. Eran atacados por igual los estudiantes como también los académicos presentes en la plaza universitaria. Se calcula que las fuerzas gubernamentales que entraron contaban con más de 2 mil 500 miembros fuertemente armados con balas y gases lacrimógenos. Después de la opresión dentro del espacio universitario, la lucha se trasladó a las calles de la ciudad, atacando también accidentalmente a la población civil cercana ${ }^{26}$.

Los alumnos y profesores de la Universidad eran vistos como parásitos e inútiles en la vida productiva del país. Casi inmediatamente se iniciaron los arrestos de los líderes estudiantiles y se sembró el terror entre los otros ${ }^{27}$.

\section{Protesta estudiantil, marzo 68. (¡Obreros! No se dejen provocar contra nosotros)}

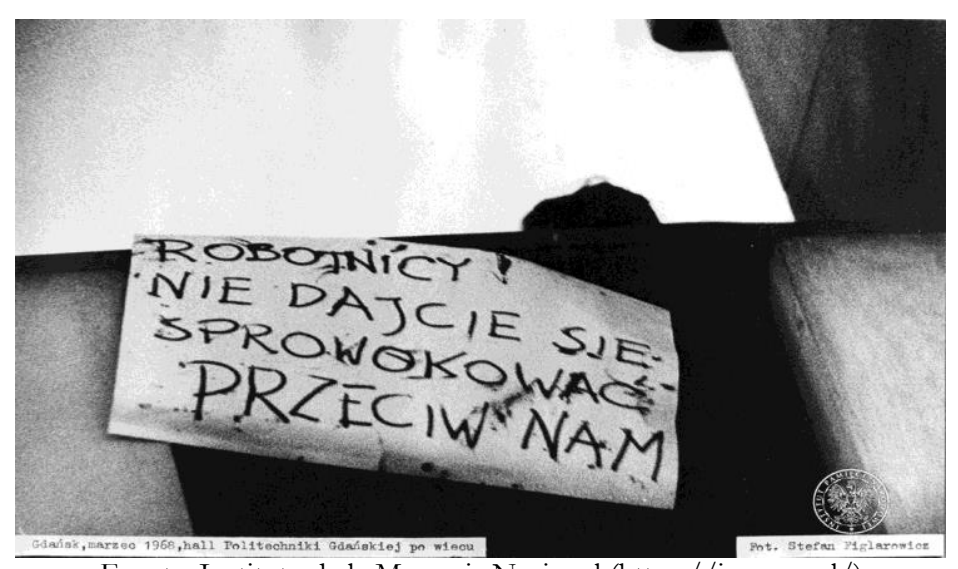

Las noticias sobre el descontento en Varsovia corrieron por Polonia. Los estudiantes de educación media superior y superior de otras ciudades organizaron las manifestaciones a favor de sus compañeros y fueron brutalmente golpeados y arrestados por la milicia. Al mismo tiempo el gobierno organizó las marchas obreras que expresaron el descontento hacia la juventud y los tacharon como hippies, niños flores y mariguaneros influenciados por la cultura occidental. ${ }^{28}$

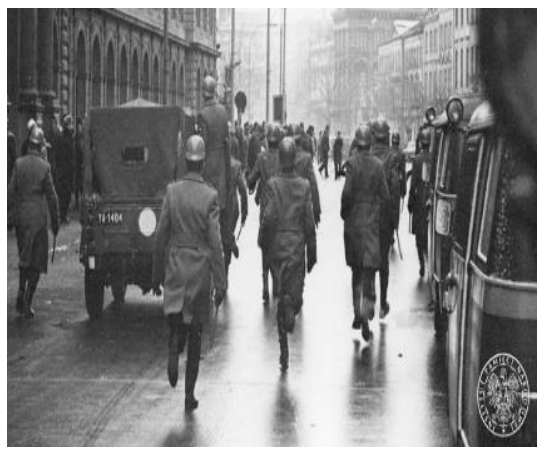

Protesta estudiantil, marzo del 68

Fuente: Instituto de la Memoria Nacional (https://ipn.gov.pl/)

Para ese tiempo ya era difícil parar la crítica social hacia el gobierno, quien aumentó la opresión en contra de la oposición. Los inconformes fueron apoyados ampliamente por la Iglesia Católica Romana y la sociedad exigía al gobierno responder a las preguntas y dudas que la comunidad estudiantil plateaba acerca de la libertad de expresión, implementación de la democracia y acciones en contra de la corrupción. El movimiento era apoyado

${ }^{26}$ Jacek Kuroń, Międyy Październikiem '56 a Marcem '68, http://otwarta.org/wp-content/uploads/2011/11/Marzec-68lekki.pdf

27 Wojciech Roszkowski Historia Polski 1945-2005 (Historia de Polonia 1945-2005), Wydawnictwo Naukowe PWN, 2006.

28 A los estudiantes se les presentaba en la propaganda oficial como buenos para nada, parásitos o simplemente como traidores de Polonia. 
por la elite cultural e intelectual del país. ${ }^{29}$ Como respuesta, el gobierno cerró las facultades de ciencias sociales y humanidades en las universidades (entre ellas las carreras como economía, filosofía, sociología). A muchos estudiantes se les prohibió continuar con sus estudios e inmediatamente después iniciaron los despidos de profesores ${ }^{30}$.

A finales de marzo la situación ya era controlada por el gobierno. Los reclamos de los jóvenes no encontraron el apoyo en la sociedad. La propaganda oficial los presentaba como espías capitalistas, como los traidores del movimiento obrero y finalmente - basándose en los sentimientos antisemitascomo un complot judío contra los polacos. ${ }^{31}$ En todo el país se organizaron manifestaciones en las fábricas en las cuales se gritaba: estudiantes a estudiar, escritores a escribir, castigar a los provocadores, sionistas a Sion, Moshe 32 a Israel. Dentro del descontento que se generó, el primer secretario del Partido Obrero Unificado Polaco (POUP), Vladislao Gomulka, buscaba a los responsables, pronunciando el discurso que despertó la ola de antisemitismo y persecución de los judíos:

El gobierno polaco trata a todos los ciudadanos igual, sin importar la etnia, cada ciudadano tiene los mismos derechos, pero también las mismas obligaciones. Pero no queremos que se forme la $\mathrm{V}$ Columna $^{33}$ (aplausos). No podemos ser tibios en los tiempos de la amenaza de paz mundial, tampoco cuando la seguridad de Polonia está amenazada. Responsables por esto son los que apoyan al agresor y al imperialismo. Que sientan que están en la mira, independiente de la etnia, que sacan las conclusiones (aplausos) $)^{34}$.

Primer secretario del Partido Obrero Unido Polaco, Vladislao Gomulka. Discurso condenatorio de marzo del 68.

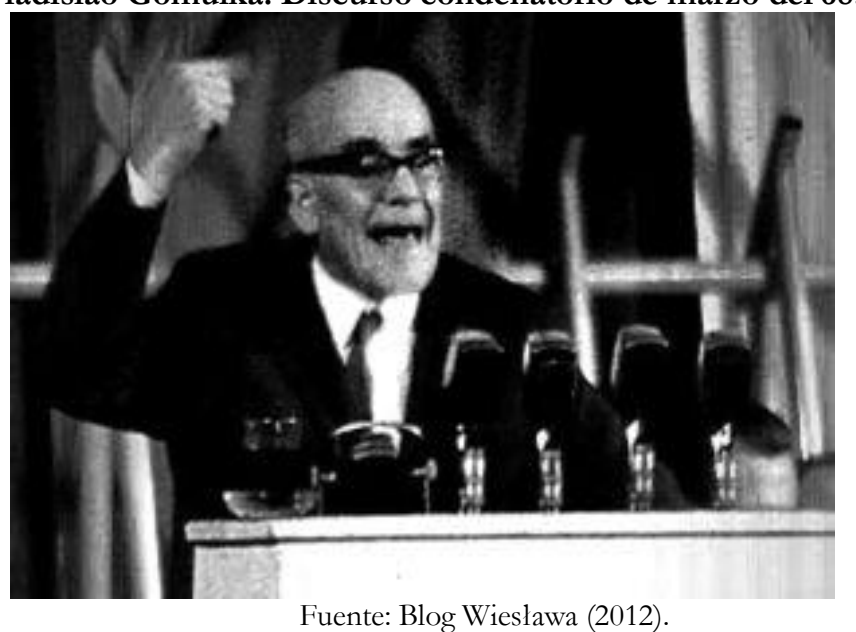

La situación que se presentó fue aprovechada por el POUP, que entonces gobernaba haciendo las purgas internas contra los supuestos infiltrados. Para defenderse, el primer secretario del partido, Vladislao Gomulka, dio un discurso en el que condenó las manifestaciones de los estudiantes: "una parte

\footnotetext{
${ }_{29}$ Desde los movimientos de 1956 se formó un grupo de intelectuales y de gente relacionada con la cultura que criticaban el autoritarismo y corrupción del gobierno.

30 Jerzy Eisler Marzec 1968. Geneza-przebieg-konsekwencje (Marzo 1968. Génesis - trayectoria-consecuencias), Warszawa, PWN, 1991.

$31 \mathrm{El}$ antisemitismo polaco, como en el resto del continente europeo, tiene sus raíces en siglo XIX y especialmente en el periodo entre la Primera y Segunda Guerra Mundial relacionado con los movimientos totalitarios como falangismo, fascismo y nazismo. 32 Un insulto polaco al judío, Moshe era unos de los nombres muy comunes entre los judíos polacos.

33 Referencia que se hace a la actividad y espionaje alemán nazi antes de la II Guerra Mundial dentro de la sociedad polaca en 1939.

34 Dariusz Stola, Kampania antysyjonistyczna w Polsce 1967-1968, (Campania antisemita en Polonia 1967-68) Warszawa, p.274, 2000.
} 
de los jóvenes [...] era engañada por las fuerzas que son enemigas del socialismo. Estas fuerzas sembraron entre los alumnos anarquía y falta de la ley. Provocando los sangrientos disturbios en las calles" 35 .

En el discurso de Gomulka también se mencionó el complot judío, lo que desató las purgas de los elementos incómodos o simplemente de aquellos que no querían soltar el poder, primero dentro del partido y posteriormente se extendió a nivel social. Hasta hoy se sabe muy poco acerca de los acontecimientos de este periodo, pero los datos oficiales mencionan que más de 8 mil personas perdieron su trabajo. ${ }^{36}$ Fueron arrestados más de 2 mil 700 estudiantes y otros miles relegados de los espacios universitarios. Muchos que eran o se sospechaban que podían ser de origen judío, fueron obligados al exilio. Wojciech Roszkowski menciona en su libro que:

Los comunistas trataron de movilizar en Polonia, en marzo de 1968, las más oscuras fuerzas escondidas en cada sociedad - chovinismo, racismo y xenofobia- y gracias a esto esconder las verdaderas causas de la crisis y aprovecharse para hacer las purgas políticas, desacostumbrar a los polacos a pensar racionalmente y hacerlos sus cómplices en la lucha contra un enemigo imaginario ${ }^{37}$.

Los condenados a prisión recibieron un trato especial consistente en salir al exilio sin posibilidad de regresar al país, a cambio de evitar la cárcel; en tanto que las aduanas les recogieron todos los documentos polacos para imposibilitar su regreso. Se considera que salieron alrededor de 35 mil judíos (de los 40 mil que quedaron después de la Segunda Guerra Mundial), entre los que se encontraban unos 500 intelectuales involucrados en las protestas del marzo $68^{38}$.

Es importante recordar que antes de la Segunda Guerra Mundial, Polonia era el país con más población judía del mundo, aproximadamente 3 millones 800 mil personas que representaban el 10\% de la población total. A pesar de que una parte importante de ellos apoyaba las ideas socialistas, el antisemitismo era uno de los problemas que asechaban a la sociedad, como ocurría en otros países europeos durante el periodo de entreguerras. La mayoría de los judíos perdieron la vida durante el Holocausto y posteriormente se dividieron entre los socialistas que apoyaban el régimen comunista y los que comenzaron a criticarlo por desviarse de las ideas originales del socialismo ${ }^{39}$. El sociólogo, Zygmunt Bauman ${ }^{40}$, así describía la situación y emociones cuando dejó Polonia a causa de la persecución de los judíos, como unas de las consecuencias de la persecución de los judíos:

Situación social en el país en marzo. Callada, pero misteriosa y que tiene muchas causas de descontento de la clase obrera, enérgica y esperanzada juventud, desilusionados círculos de intelectuales, la clase media muy frustrada y sobre todo temerosa, la cúpula del poder insegura de todo y de todos. Esta es la situación que según todas las reglas y análisis leninistas se denomina como revolucionaria ${ }^{41}$.

Del movimiento en marzo 68 se aprovecharon las autoridades para hacer las purgas de los opositores y establecer una nueva élite en el poder que ya esperaba su turno. Los acontecimientos del marzo polaco eran resultado de una serie de descontentos hacia el gobierno que se decía socialista y la corrupción que le caracterizaba en todos los sentidos. Eran también parte de una larga serie de rebeliones

\footnotetext{
35 Archiwum Centrum Karta (Archivo Centro Carta), 1968,

36 Hasta hoy no se han podido encontrar mayores datos.

37 Wojciech Roszkowski, Historia Polski 1945-2005 (Historia de Polonia 1945-2005), Wydawnictwo Naukowe PWN.p.167.

38 Krystyna Kersten, Polacy, zydri, komunisci. Anatomia polprawdy 1939-68 (Polacos, judios, comunistas. Anatomía de semi verdades 193968). Warszawa, NOW, 1992.

39 Wojciech Roszkowski, Historia wspolczesna Polski 1914-2011 (Historia contempornea de Polonia 1914-2011) (wydanie 7-tomowe), Świat Książki, 2011.

40 Bauman era catedrático en la Universidad de Varsovia.

${ }^{41}$ Zygmunt Bauman, O frustracji i o kuglarzach, (Frustración y juglares), Francia, Kultura (Paryz) 1968, nr 12, s. $13-14$.
} 
sociales en la lucha por la libertad y democratización de la vida desde 1956, 1968, 1970, 1976, 1980 y hasta la caída del bloque socialista en 199142. Muchos activistas estudiantiles que participaron en los hechos de 1968 - y que habían sido encarcelados - tomaron la vía de la lucha clandestina contra el régimen y se convirtieron en los personajes emblemáticos dentro del periodo de la Solidaridad y posteriormente en la Polonia libre a partir de 1991. Nunca renunciaron a la crítica del autoritarismo y crímenes de Estado, pronunciándose a favor de las ideas socialistas y la democracia. Otra consecuencia del movimiento fue el fortalecimiento de la sociedad civil como un factor opositor al Estado, muy apegada a la Iglesia Católica Romana que apoyó a los manifestantes y se convirtió en uno de los elementos más importantes en la lucha por la democratización del país.

\section{Octubre del 68 en México}

El contexto histórico de los movimientos sociales en México 68 es parecido a los polacos. Se remonta a su historia reciente relacionándose con el régimen autoritario del Partido Revolucionario Institucional (PRI), con la opresión de la libertad de expresión, solicitudes para democratizar la vida pública, movimientos estudiantiles de los años 1942, 1949, 1952 y 1956, protestas obreras (1958 a 1965), médicas (1964), protesta michoacana de 1966 y la huelga universitaria sonorense de 1967. Todos estos fenómenos fueron aislados y sin mayor apoyo de la sociedad, lo que permitió que fueran suprimidos fácilmente por el gobierno, quien aparentaba realizar las reformas a favor de la democratización del país.

Las protestas de 1968 tenían un componente que no se había presentado antes, ya que estaban permeadas por ideas de otros movimientos sociales a nivel mundial, como las manifestaciones de Praga (Primavera en Praga) y el Mayo Francés, cuando los movimientos estudiantiles reciben un apoyo ideológico de los intelectuales, filósofos, artistas y otros. Este descontento juvenil en principio estaba contra la clase tradicionalista y conservadora y luego se convierte en las grandes protestas contra el gobierno, solicitando una sociedad más justa, incluyente y democrática.

Algunos historiadores contemporáneos como Fernand Braudel, Carlos Antonio Aguirre Rojas, Immanuel Wallerstein señalan que estaba inserto en el contexto mundial de las luchas sociales, que eran resultado de un periodo de bonanza después de la postguerra, en que cada vez más se involucraban los jóvenes universitarios. El primero que denomina los acontecimientos de 1968 como Revolución cultural fue Fernand Braudel, señalando que revolucionarían tres espacios de recreación de la cultura: la familia, los medios de la comunicación y la escuela ${ }^{43}$.

Durante el gobierno del presidente Gustavo Díaz Ordaz, en julio de 1968, en la Ciudad de México, se iniciaron una serie de manifestaciones y marchas estudiantiles, que exigían la libertad de los presos políticos, criticaban el autoritarismo del gobierno, pedían que se respetara la autonomía universitaria y apoyaban las protestas en el mundo. A los estudiantes de la Universidad Nacional Autónoma de México (UNAM) se unieron los del Instituto Politécnico Nacional (IPN) y todos los centros educativos de la Ciudad de México. Posteriormente los jóvenes recibieron apoyo de las asociaciones de maestros y sindicatos hasta convertirse en un gran movimiento social.

Los días 22 y 23 de julio ocurrieron los primeros enfrentamientos entre los estudiantes de las Vocacionales 2 y 3 del IPN y la preparatoria incorporada a la UNAM, en donde participaron los cuerpos de granaderos, quienes detuvieron a varios alumnos y entraron a las instalaciones de la escuela. ${ }^{44}$

Del 26 al 29 de julio de 1968, los alumnos de varias escuelas tomaron la decisión de entrar en un paro de labores, independientemente de la autonomía los cuerpos policiacos y el ejército nuevamente

\footnotetext{
42 Robert Bideleux, James Jeffries, A History of Eastern Europe: Crisis and Change, Routledge, 2007.

${ }_{43}$ El movimiento del 68, un legado perdurable, entrevista con Carlos Aguirre en Movimiento estudiantil en México y masacre en Tlatelolco, Ciencias Sociales Hoy, depa.fquim.unam.mx/amyd/archivero/68_Movimiento_estudiantil

${ }^{44}$ Ramón Ramírez, El movimiento estudiantil mexicano. México: Era, 1969.
} 
invadieron los espacios educativos. Los estudiantes del IPN convocaron a una reunión como protesta por la intervención en las escuelas y en demanda de la desaparición del cuerpo de granaderos y la destitución de los jefes de la policía preventiva de la Ciudad de México. Simultáneamente se organiza otra manifestación para conmemorar el XV aniversario del asalto al cuartel Moncada y en solidaridad con la Revolución Cubana, apoyando los problemas de los alumnos de las vocacionales ${ }^{45}$.

El $1^{\circ}$ de agosto el rector del UNAM; Javier Barros Sierra pronunció el discurso a favor de la autonomía universitaria y exigió la libertad de los presos políticos, retirándose a los estudiantes detenidos, encabezó la marcha con el lema estudiantil: Únete pueblo ${ }^{46}$. Al siguiente día los manifestantes comenzaron con las críticas al discurso del rector de la UNAM y se constituyen el Consejo Nacional de Huelga (CNH). Este se forma sobre tres principios: sólo estarán representadas las escuelas en huelga, no en paro activo; habrá tres representantes por escuela, elegidos en asamblea; no se admite la representación de federaciones, confederaciones, partidos o ligas, solo de escuelas. En el CNH llegan a estar representadas 75 escuelas con un total de 250 estudiantes miembros cuyas decisiones se tomaban por mayoría de votos, representaba por igual a alumnas, y reducía la animosidad entre las instituciones rivales ${ }^{47}$.

Dos días después aparecen en los periódicos las notas en las cuales se manifiesta que el gobierno de México es víctima de una conspiración organizada por las corrientes trotskistas y maoístas. ${ }^{48}$

El 4 de agosto el movimiento estudiantil elaboró otras demandas que se presentaron: derogación de los artículos 145 y 145 bis del Código Penal Federal - sobre el delito de disolución social, libertad a los presos políticos; destitución de los jefes policiacos; desaparición del cuerpo de granaderos; indemnización a los familiares de todos los muertos y heridos desde el inicio del conflicto; deslizamiento de las responsabilidades de los funcionarios culpables de los hechos sangrientos.

A finales de agosto se organizó una gran marcha desde el Museo de Antropología en la que participaron más de 30 mil personas ${ }^{49}$. En la madrugada del 28 de agosto el ejército comenzó a oprimir los campamentos estudiantiles que se quedaron vigilando después de la mega marcha. Las fuerzas armadas usaron carros blindados, patrullas de la policía preventiva, batallones de tránsito y motociclistas. Los burócratas de la Ciudad de México fueron llevados al Zócalo para manifestar su desacuerdo con los estudiantes ${ }^{50}$. El 13 de septiembre los manifestantes marcharon con los pañuelos en la boca, que se conoce como La marcha del silencio. El 18 del mismo mes, el ejército invadió Ciudad Universitaria de la UNAM.

Otro grupo peleó cuerpo a cuerpo en la entrada de la escuela con soldados que rompieron cráneos, costillas, acuchillaron muchachos; los arrastraron y subieron a camiones. ¡Asesinos! ¡Malditos! gritaban enfermeras del Hospital de la Mujer. La revista francesa L'Express informaría que en ese ataque hubo 15 muertos, y que en los combates se dispararon más de mil tiros. La información oficial del día redujo el marcador a tres muertos y 45 lesionados. Con ese exceso de violencia, el movimiento estudiantil perdió su último bastión. Cinco días antes, el Ejército había ocupado las instalaciones de la UNAM, sin un disparo, con el aplauso de los líderes del Congreso, del PRI e intelectuales, como Salvador Novo ${ }^{51}$.

Las crónicas del conflicto apuntan la toma de CU y la renuncia no aceptada del rector de la UNAM, Javier Barros Sierra, como los eventos más relevantes de esos días, marcados, sin embargo, con sangre. La desarticulación del movimiento era progresiva: Heberto Castillo, quien dio El Grito en CU la

\footnotetext{
45 Sergio Aguayo Quezada, 1968: los archivos de la violencia. México: Grijalbo-Reforma, 1998.

46 Gastón García Cantú, Javier Barros Sierra. México: Siglo XXI Editores, 1972.

47 Ramón Ramírez, El movimiento estudiantil mexicano. México: Era, 1969.

48 Salvador Hernández, El PRI y el movimiento estudiantil de 1968. México: Ediciones El Caballito, 1971.

49 Ramón Ramírez, El movimiento estudiantil mexicano. México: Era, 1969.

50 Idem.

51José Revueltas, México 68: juventudy revolución. México: Era, 1978.
} 
noche del 15, desde el 18 vivió escondido hasta su captura; Eli de Gortari fue detenido el 23. Lecumberri los recibiría. 52

A mediados de septiembre el ejército entró a la Ciudad Universitaria oprimiendo el Consejo Nacional de Huelga que se había formado para representar a todos los inconformes. En ese momento se calcula que había una docena de muertos y alrededor de 100 detenidos o desaparecidos ${ }^{53}$. Los enfrentamientos en Ciudad Universitaria se hicieron cada vez más violentos. A finales de septiembre se denunciaba la presencia de un agrupamiento denominado Batallón Olimpia, el cual originalmente estaba destinado a cuidar las instalaciones olímpicas, luego pasó a ser un grupo de choque responsable de varios enfrentamientos callejeros con los estudiantes de diferentes vocacionales y preparatorias. Después este grupo participó en la masacre de Tlatelolco ${ }^{54}$.

El ejército se retiró de las instalaciones de la UNAM y del IPN el $1^{\circ}$ de octubre. Un día después, el 2 de octubre, miles de personas se reunieron en la Plaza de la Tres Culturas en Tlatelolco. En la tarde del mismo día por medio de la provocación se inició el ataque a las multitudes. Muchos manifestantes que lograron escapar del tiroteo se escondieron en los edificios cercanos a la plaza, pero fueron alcanzados por los grupos de militares, policías y paramilitares. Se calcula que arrestaron a alrededor de 3 mil estudiantes. Aún se desconoce el número de muertos, pero el gobierno mexicano confirmó 28 fallecidos. Elena Poniatowska, en su libro La noche en Tlatelolco menciona que se contaron los 65 cadáveres en el lugar; el periodista inglés John Rodda calculó en sus investigaciones independientes que hubo 250 muertos. También murió un soldado ${ }^{55}$.

Protesta estudiantil, octubre 68

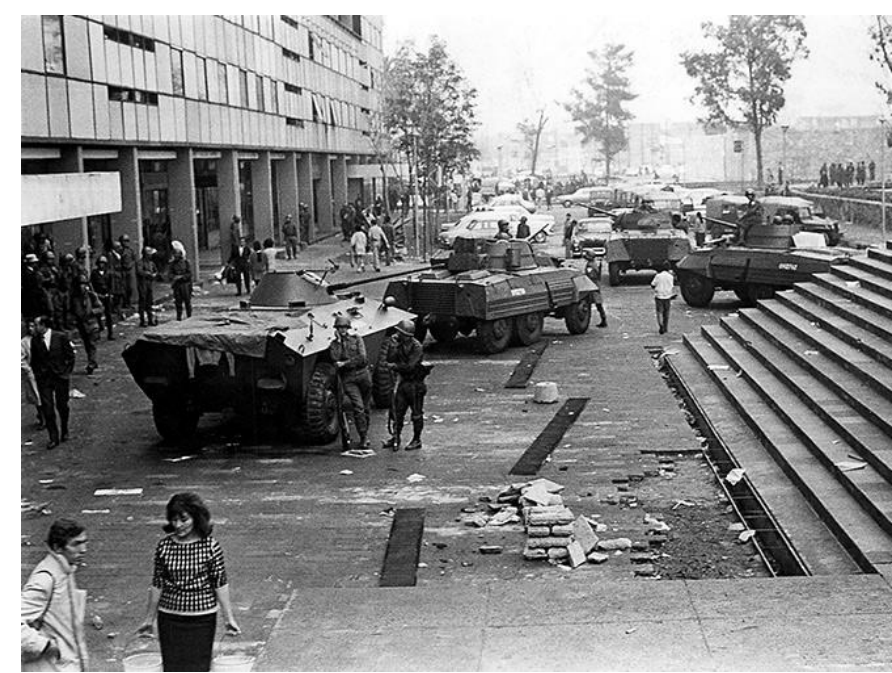

Fuente: Regeneración (https://regeneracion.mx/matanza-de-tlatelolco-1968)

En 1999 el periodista Julio Scherer y el escritor Carlos Monsiváis publicaron Parte de Guerra, libro en el que se hicieron públicas las memorias del entonces secretario de Defensa Nacional, Marcelino García Barragán. En este documento, el responsable del Ejército en 1968 señala que la orden de disparar contra los estudiantes provino del Estado Mayor Presidencial, encabezado por el general Luis Gutiérrez

\footnotetext{
52 Juan Arvizu Arrioja, México 68: Toman Casco de Santo Tomás tras 12 horas de combate, El universal, México, 22 September 2008, http://archivo.eluniversal.com.mx/notas/540219.html

53 José Revueltas, México 68: juventudy revolución. México: Era, 1978.

54 Sergio Aguayo Quezada, 1968: Los archivos de la violencia. México: Grijalbo-Reforma, 1998.

55 John Rodda, The Killer Olimpics, The Guardian, 18-VIII-1972.
} 
Oropeza, y que las tropas del Ejército respondieron a una agresión de otro grupo de militares agrupados en el Batallón Olimpia ${ }^{56}$.

Protesta estudiantil, octubre del 68.

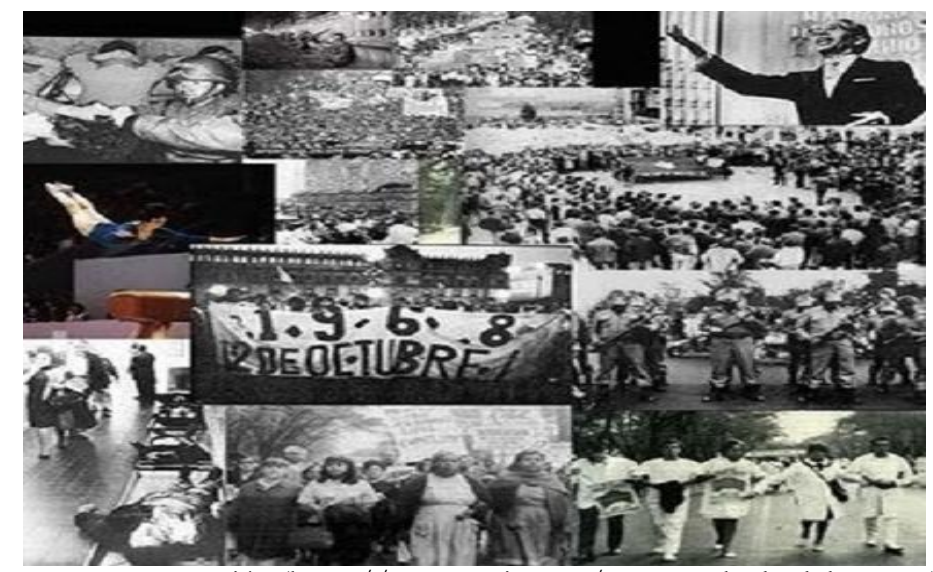

Fuente: Regeneración (https://regeneracion.mx/matanza-de-tlatelolco-1968)

El gobierno de México utilizó toda una estrategia de sabotaje, infiltración y una campaña de desprestigio en los medios de comunicación, principalmente en El Universal, El Sol de México, La Prensa o en El Heraldo desde las primeras semanas de su desarrollo hasta la masacre en Tlatelolco. Se ejerció una fuerte censura a la libertad de expresión y se emplearon palabras de desprestigio respecto al movimiento estudiantil ${ }^{57}$. En diferentes medios de comunicación los manifestantes eran llamados saboteadores y agitadores, así como también terroristas, mitin de los huelguistas hasta manos extrañas que querían desprestigiar a México. Los medios internacionales como por ejemplo BBC o New York. Times dieron cobertura a los hechos. Una protesta estudiantil evidenció el carácter autoritario del sistema político mexicano, los abusos de la policía y se convirtió en un movimiento social de defensa de los derechos democráticos. El 68 expresa también las batallas culturales y luchas políticas. Se convirtió en un movimiento y un fenómeno político, cultural y moral, que inició cambios sustanciales dentro de la sociedad mexicana.

\section{Conclusiones}

La naturaleza humana parece buscar las ideas y valores de justicia, igualdad, libertad de expresión, luchar contra la corrupción y el fraude; todos estos a favor de la democratización, independientemente de los tiempos históricos y espacios geográficos. Las protestas de los años sesenta del siglo pasado son una continuación de la larga lucha de la humanidad por la libertad, como también manifiesta la necesidad de cambios culturales y sociales. De manera muy similar, el gobierno polaco y mexicano se aprovecharon de los disturbios preparando el cambio del poder y haciendo las purgas de los elementos incómodos dentro de sus filas.

Los movimientos estudiantiles de 1968 de Polonia y México toman parte de la historia de todos nosotros. Comparten muchas similitudes como la lucha a favor de la democratización de la vida pública, de la justicia y libertad de expresión, contra los gobiernos corruptos y autoritarios. Los jóvenes formados en diferentes ambientes culturales y políticos soñaban con cambiar el sistema y la sociedad. Desprestigiados por la propaganda oficial como maleantes, terroristas, parásitos o buenos para nada no

${ }^{56}$ Jesús Ramírez Cuevas, La matanza de Tlatelolco y la herencia 1968 en https:/ / regeneracion.mx 2 de octubre 2017, 2017.

${ }^{57}$ Jefferson Morley, Nuestro hombre en México: Winston Scott y la historia oculta de la CLA. Santillana Ediciones Generales, 2011. 
lograron obtener la solidaridad de la sociedad, oprimida y temerosa de las consecuencias. Pagaron el precio más alto: la vida y la libertad. Aunque dejaron el mensaje de que los cambios pueden ser posibles con mejor organización y la unión de todos los grupos sociales, con la esperanza de un mejor futuro que nunca muere.

En el caso polaco las causas de los movimientos estudiantiles fueron diferentes dado que Polonia tenía un sistema socialista impuesto por la fuerza después de la Segunda Guerra Mundial, mientras que México contaba con un sistema capitalista, dividido social y económicamente en clases marcadamente desiguales, pero la reacción de los jóvenes fue parecida. Ambos compartieron el carácter oposicionista frente al gobierno fallido, señalaron las debilidades y necesidades de cambios en las áreas donde a la sociedad se le dificultó funcionar correctamente. Fue un acto de desobediencia cuando no existía otra manera de cambiar ni corregir el sistema político. Como se observa en la teoría de la sociología:

Hay estados que se resisten a permitir que la población participe en la vida política. El autoritarismo es un sistema político que impide la participación popular en el gobierno independientemente del tiempo, espacio y sistema económico. Un gobierno autoritario no solo es indiferente a las necesidades del pueblo, sino que carece de mecanismos legales necesarios para destituir a quienes ocupan el poder, y no proporcionan a la población ningún (o casi ningún) medio para que exprese su opinión ${ }^{58}$.

El sociólogo polaco Wlodzimierz Wesolowski resume lo que es el autoritarismo del siguiente modo: "La filosofía autoritaria defiende la supremacía del Estado sobre otras actividades sociales" ${ }^{59}$. La falta de fuentes y datos precisos acerca del número de muertos, desaparecidos u obligados a salir fuera del país, creó espacios vacíos y silencios que en la historia algunas veces nos dicen mucho más que la abundancia de documentos.

La sociedad polaca y mexicana después de los sucesos de 1968 visiblemente han cambiado. La conciencia y participación ciudadana aumentaron, Polonia y México ya no son los mismos de antes. En Polonia el movimiento clandestino, que se fortaleció con Marzo del 68, se convirtió en la Solidaridad de 1980, que conmovió a todo el bloque socialista, iniciando una serie de cambios democráticos que finalmente derribaron al régimen que se decía socialista. Su influencia llegó a otros Estados que se encontraban dentro de la Cortina del Hierro. México todavía está esperando a su oportunidad.

\section{Referencias bibliográficas ${ }^{60}$ :}

\section{Fuentes impresas:}

\section{Libros, artículos en revistas y prensa}

Aguayo Quezada, Sergio, 1968: los archivos de la violencia. México: Grijalbo-Reforma, 1998.

Altbach, Philip, Comparative Higher Education, Greenwood Publishing Group, 1998.

Aranda Sánchez, José, El Movimiento Estudiantily la Teoría de los Movimientos Sociales, Convergencia. Revista de Ciencias Sociales, vol. 7, núm. 21, enero-abril, 2000 Universidad Autónoma del Estado de México Toluca.

Arendt, Hannah, Niepostuszeństwo obywatelskie (Desobediencia civil), Aletheia, Warszawa, 1999. Bauman, Zygmunt, O frustracii i o kuglarzach, (Frustración y juglares,) Francia, Kultura (Paryz) 1968, nr 12.

58 John Macionis, Ken Plummer, Sociología, Pearson Educacion. p. 464, 2007.

59 Wojciech Wesolowski, Klasy, warswy i wladza (Clases, estructuras y poder), Polonia, PW, p. 101., 1990.

${ }^{60}$ Toda literatura polaca es con la traducción libre de I. Tkocz. 
Bauman, Zygmunt, The Present Crisis of the Universities, en: Leszek Nowak, Jerzy Brzeziński, Poznań Studies of the Philosophy of Science and the Humanities 50: The Idea of The University, Rodopi, Amsterdam, 1995. Bideleux, Robert, James Jeffries, A History of Eastern Europe: Crisis and Change, Routledge, 2007

Eisler, Jerzy, Marzec 68. Genesis -pręebieg - konsekwencje (Marzo 1968. Génesis - trayectoria-consecuencias), Warszawa, PWN, 1991.

Eisler, Jerzy, Polskie miesiace, caylli kryzysy(y) w PRL (Los meses polacos, crisis en Polonia),Polonia, Wyd. EPUB, 2008.

Eisler, Jerzy, Rok polski 68 (Año polaco 1968), Warszawa, PWN, 2006.

Finkelstein, Norman, La industria del Holocausto, Verso, 2003.

García Cantú, Gastón, Javier Barros Sierra. México: Siglo XXI Editores, 1972.

Gustav, Jung, (2002), Los arquetipos y lo inconsciente colectivo. Madrid: Trotta

Hernández, Salvador, El PRI y el movimiento estudiantil de 1968. México: Ediciones El Caballito, 1971.

Hillebrandt, Bogdan, Maržec 1968. Geneza i przebieg wypadków, (Marzo 1968, genesis y trayectoria de los eventos), Polonia, Warszawa, 1986.

Kersten, Krystyna, Polacy, zydri, komunisci, Anatomia pol-prawdy 1939-68 (Polacos, judios, comunistas. Anatomía de semi verdades 1939-68). Warszawa, NOW, 1992

Maciejewski, Jaroslaw, Zofia Trojanowicz, Požnański cžerwiec 1956 (Poznań - Junio 1956), Poznań, 1981.

Macionis, James, Ken Plummer, Sociologia, Pearson Education, 2007.

Monsiváis, Carlos, Julio Scherer, La parte de Guerra, México, Nuevo Siglo, 1000.

Morley, Jefferson, Nuestro hombre en México: Winston Scott y la bistoria oculta de la CIA. Santillana Ediciones Generales, 2011.

Paczkowski, Andrzej, Pót wieku driejón Polski (Medio siglo de la historia de Polonia). Warszawa: Wydawnictwo Naukowe PWN, 2005.

Poniatowska, Elena, La noche en Tlatelolco. Testimonios de historia oral. México, Era, 1993.

Ramírez, Ramón, El movimiento estudiantil mexicano. México: Era, 1969.

Revueltas, José, México 68: juventud y revolución. México: Era, 1978.

Rodda, John, The Killer Olimpics, The Guardian, 18-VIII-1972.

Roszkowski W., Wojciech, Historia Polski 1945-2005 (Historia de Polonia 1945-2005), Wydawnictwo Naukowe PWN, 2006.

Roszkowski, Wojciech, Historia wspolczesna Polski 1914-2011 (Historia contempornea de Polonia 19142011) (wydanie 7-tomowe), Świat Książki, 2011.

Stola, Dariusz, Kampania antysyjonistyczza w Polsce 1967-1968 (Campania antisemita en Polonia 1967-68), Warszawa, 2000.

Suleja, Wojciech Marzec na Dolnym Slasku 68 - anatomía protesty (Marzo 68 en Silesia Baja - anatomia de la protesta), Warszawa: Instytut Pamięci Narodowej, 2006.

Wesolowski, Wojciech, Klasy, warswy i wladza (Clases, estructuras y poder), Polonia, PW, 1990.

El Heraldo, 1968.

El Sol de México, 1968.

El Universal, 1968.

La Prensa, 1968.

\section{Fuentes digitales:}

Archivo Centro Carta (Archiwum Centrum Karta), 1968

https://ipn.gov.pl/.http://www.xxwiek.karta.org.pl/

Arvizu Arrioja, Juan, México 68: Toman Casco de Santo Tomás tras 12 horas de combate, El universal, México, 22

September 2008, https://archivo.eluniversal.com.mx/notas/540219.html 
Blog Wiesława, Przemówienie na spotkaniu z. warszawskim aktywem partyjnym uygloszone 19 marca 1968, http://wieslaw1956.blogspot.com/2012/10/przemowienie-na-spotkaniu-z-warszawskim.html

El movimiento del 68, un legado perdurable, entrevista con el doctor Carlos Aguirre en Movimiento estudiantil en México y masacre en Tlatelolco, Ciencias Sociales Hoy, http://depa.fquim.unam.mx/amyd/archivero/68 Movimiento estudiantil en Mexico 1968 y masac re de Tlatelolco Weblog Ciencias sociales 31744.pdf

Instituto de la Memoria Nacional (IPN), https://ipn.gov.pl/

Kosciankowski, Roman, Kontrola nastrojow $i$ komentarzy wsrod spoleczensktwa w zwiąku zprocesami poznañskich robotnikow w $1956 r$ (Control y censura de los comentarios en la sociedad relacionada con los procesos de los obreros de Poz̧nan en 1956) w Jaroslaw Maciejewski, Zofia Trojanowicz, Poznański czerwiec 1956 (Poz̨nán - Junio 1956), Poznań 1981, http://cejsh.icm.edu.pl/cejsh/element/bwmeta1.element.desklight-c57782a2-9d4d-4af69c77-47e1f0cac8d2/c/251-262 Koscianski.pdf

Kuroń, Jacek, Miedsyy Październikiem '56 a Marcem '68,

http://otwarta.org/wp-content/uploads/2011/11/Marzec-68-lekki.pdf

Leszkowicz, Tomasz, Co sie zdarayto 8 marca 1968 roku?. bttps: / histmag.org/

Ramírez Cuevas, Jesús La matanz̧a de Tlatelolco y la berencia 1968 en https://regeneracion.mx 2 de octubre 2017

Regeneración, http://regeneracion.mx/matanza-de-tlatelolco-1968 